\title{
"La obvia inferioridad de nuestras escuelas...". Las primeras influencias norteamericanas en el Trabajo Social chileno a inicios de la década de los 40
} "The obvious inferiority of our programs..." early american influences on Chile's social work profession during the 1940s

\author{
Maricela González Moya \\ Universidad Santo Tomás, Escuela de Trabajo Social. Asistente Social, Magíster en Filosofía, Doctora@ en Historia. \\ Correo electrónico:mgonzalez@santotomas.cl
}

\begin{abstract}
Resumen
El artículo muestra la influencia norteamericana en el Trabajo Social chileno que comenzó a inicios de la década del 40 del siglo XX y que remplazó al ascendente europeo que había tenido la profesión en sus primeros quince años de existencia. Desde el enfoque teórico de la historia global, se indaga en el proceso de contactos recíprocos que se produjeron entre Estados Unidos y Chile, intentando trascender la perspectiva puramente imperialista o dependentista con que ha sido abordado tradicionalmente el tema. Así, se busca mostrar esta área de influencias como una "zona de contactos" donde priman los intercambios culturales que operan al alero de la hegemonía estadounidense post segunda guerra mundial y de la doctrina del "buen vecino" de Roosevelt.

Palabras clave: Historia del Trabajo Social, profesionalización, norteamericanización.

Summary

This paper analyzes the United States' influence on Chile's social work profession, which began in the 1940s and replaced the European basis of the profession during its first 15 years. Using a global history theory approach, we analyze mutual contacts between Chile and the United States in an attempt to transcend the purely imperialist or dependancy perspectives traditionally used to study the issue. From this perspective, the US' influence occurs as a "contact zone" based primarily on cultural exchanges that operate under post World War II US hegemony and Roosevelt's "good neighbor" doctrine.
\end{abstract}

Key words: Social work history, professionalization, americanization.

\begin{abstract}
“... No pretendo analizar los factores que dan superioridad sobre el nuestro, al Servicio Social de los Estados Unidos y en los que se cuentan, de seguro, mejores condiciones económicas, culturales y de otra especie".

Luz Tocornal de Romero, Directora de la Escuela de Servicio Social. Palabras pronunciadas el año 1941, después de viajar a Estados Unidos.
\end{abstract}

Introducción y perspectivas de análisis

El presente artículo busca analizar, desde la perspectiva de la historia global, las relaciones que tuvieron las escuelas de servicio social chilenas con las influencias internacionales, y específicamente la norteamericana, en torno al año 1940. La tesis central de nuestro trabajo descansa en la idea de que en ese año comenzó un influjo decisivo de Estados Unidos en la historia de la profesión, ascendencia que se mantendría hasta bien entrados los años 70 . El papel que jugaron los elementos foráneos en los inicios del Trabajo Social chileno ha sido interpretado, básicamente, desde una matriz crítica y se han calificado a menudo como influencias alienantes, 
ajenas a las necesidades latinoamericanas, forasteras y subordinantes. El año 1970 la editorial de la Revista de Trabajo Social de la Universidad Católica afirmaba que el dominio europeo y norteamericano de los primeros años profesionales condujeron a la apropiación de "métodos empapados de la realidad de los países en los cuales se gestó" (Revista de Trabajo Social, 1970, p. 3). La dependencia latinoamericana se manifestó "en el uso de teorías y metodologías elaboradas en otros países, sin adecuarlos a nuestra realidad. En la ausencia de teoría propia se pretendió desarrollar la profesión según las modalidades que esta iba adoptando en otros países (Estados Unidos, principalmente). Esta dependencia condicionó también la orientación que se dio al bienestar social, área específica en la cual se han ubicado en su mayoría los trabajadores sociales" (Aylwin, Poblete y Solar, 1970, p. 5). De esta manera, "el gran legado" de la tradición europea y norteamericana habría sido la persistencia de una tradición voluntarista y asistencialista (Aylwin y Rodríguez, 1971, p. 5), plagada de elementos rutinarios y de mucha improvisación en el actuar profesional (Alvariño, 1974).

Este criticismo estuvo influido por las teorías de la dependencia y del imperialismo que desde las décadas de los 60 y 70 impugnaron a los modelos difusionistas del desarrollo, de acuerdo a los cuales existe una dicotomía entre países "desarrollados" y otros "en vías de desarrollo" y que estos últimos replican una dualidad interna que se expresa en la existencia de un sector "rural atrasado" y un sector urbano "capitalista y moderno". Los nuevos enfoques disidentes cuestionaron la teoría de la modernización, pero mantuvieron intacta la partición entre extranjeros y locales y se siguió amarrado a un modelo teleológico de progreso.

En particular, la teoría del imperialismo se concentró en el análisis de la penetración norteamericana en la periferia latinoamericana, especialmente referida a los ámbitos políticos, económicos y militares. "Preocupada sobre todo por la cuestión de la disparidad de las relaciones de poder entre los estados naciones y por las tensiones generadas por las exportaciones de capital a formaciones sociales que se encontraban en una fase menos 'avanzada' de desarrollo, esta concepción presentó la creciente y multifacética conexión entre Estados Unidos y América Latina como una relación entre dos entidades políticas y dos economías distintas, y suele caracterizar a los empresarios, diplomáticos y militares norteamericanos en el exterior como instrumentos de una alianza entre el capital y el estado para conquistar merca- dos, aprovechar fuentes baratas de materias primas y consolidar una relación asimétrica de poder" (Gilbert, 2005, p. 102).

De manera similar, los modelos de dependencia y sistemas mundiales señalan las asimetrías en el comercio y las finanzas internacionales y cartografían la forma en que las elites dirigentes, los partidos políticos y la sociedad civil se han hecho partícipes de la reproducción de las condiciones estructurales de "dependencia" que impiden que los países "periféricos" puedan generar los niveles de desarrollo de las "metrópolis".

En síntesis, "la narrativa maestra de la "dependencia', como la del 'imperialismo', presupuso una relación bipolar que subsumía la diferencia (regional, de clase, racial/étnica, de género, generacional) al servicio de una maquinaria más grande que fijaba límites, extraía plusvalías, establecía jerarquías y modelaba identidades. En su descripción, ambas narrativas pusieron a Estados Unidos (o a las 'naciones centrales' del sistema mundial) al control de una gran empresa 'neocolonial', que manejaba una corriente de flujos unificados por la lógica de la ganancia, el poder y una única cultura hegemónica. Desde el centro fluían las mercancías, el capital, la tecnología, los artefactos culturales y el poder, el conocimiento técnico y los equipos militares, a fin de reproducir más de lo mismo" (Gilbert, 2005, p. 103). De esta manera, el imperialista pasó a ser demonizado y el calificativo se extendió no solo hasta las corporaciones económicas o políticas, sino que alcanzó a los planificadores de políticas, a los promotores culturales e incluso a los centros de educación superior.

Como corolario de lo anterior, la visión de los sujetos "dependientes" era fatalista, a pesar de que se buscaba algún tipo de cambio revolucionario. los campesinos, los obreros y los actores urbanos aparecían pasivos y dormidos, carentes de protagonismo. La esfera de la cultura quedaba relegada por el predominio del análisis economicista y la "imposición del estilo de vida norteamericano" no era más que una consecuencia obvia de un afán por hacer penetrar en las periferias las mercancías producidas por el capitalismo.

Proponer una interpretación desde la óptica de la historia global significa que se ha buscado trascender las visiones del "imperialismo" y la "dependencia" como perspectivas que priorizan las relaciones de poder unilaterales y unidireccionales, y trata de reemplazarlas por la idea de las "zonas de contacto", esto es, que sin negar la influencia de la política, la economía y la cultura norteamericanas, el poder 
es y ha sido ejercido de manera desigual y diversa en distintas regiones y por distintos agentes, en una variedad de lugares y potenciando arreglos internacionales múltiples (Gilbert, 2006, p. 5). Como señala Joseph: "Las formas de poder han sido múltiples y complejas: simultáneamente han operado a través de los estados-naciones y de las relaciones regionales más informales; a través de los negocios y las redes comunicacionales y las industrias culturales; a través de las instituciones científicas y las agencias filantrópicas; mediante las tecnologías importadas; y por medio de las construcciones de nacionalidad, raza, etnicidad, género y sexualidad. Las zonas de contacto no son lugares geográficos con significaciones estables; pueden representar dominio y hegemonía, pero son, simultáneamente, sitios de negociación, préstamo e intercambio; y de redistribución e inversión" (Gilbert, 2006, p. 5) ${ }^{1}$.

De lo que se trata es de reconceptualizar la relación entre Estados Unidos y América Latina, enfatizando en una nueva comprensión de las relaciones complejas entre cultura y poder, donde no se desconoce la asimetría ni la existencia de verdaderas maquinarias imperiales de dominio, sino que se integran las interacciones, la conectividad y las múltiples y polivalentes representaciones discursivas y materiales que se gestan en esas "zonas de contacto". En ese sentido, la perspectiva de la historia global trata de superar el eurocentrismo y, a la vez, los latinoamericanismos extremos, en un afán por acentuar los entrelazamientos y anular la teleología como fondo histórico-filosófico (Conrad y Eckert, 2007).

De esta manera, lo que intentamos en este artículo es encontrar y mostrar las conexiones que existieron entre el Trabajo Social chileno y el norteamericano desde los '40 en adelante, no ya para inscribir esas relaciones en la lógica del centro-periferia, sino para analizar los matices y complejidades que tuvo, las formas que adoptó y los procesos que ayudó a configurar. La elección misma del tema resulta relevante desde este enfoque, toda vez que explora en las relaciones culturales, y específicamente en el intercambio intelectual y la historia de las profesiones, que a menudo no ha sido considerado como significativo en los enfoques clásicos sobre el tema. Salvo por el libro de María Angélica Illanes (Illanes, 2007), la aproximación historiográfica al tema del Trabajo Social en Chile ha sido casi inexistente. En ese sentido, han sido siempre los propios trabaja- dores sociales los que han escrito su historia y esos abordajes han adolecido de algunas limitaciones más o menos obvias: reducción de la historia profesional a "etapas" subsidiarias del contexto, rígidas y canonizadas esquemáticamente; escasa referencia a fuentes primarias, y debilidad metodológica en términos de acceso crítico a los documentos escritos y orales $^{2}$. Esta historia desde el Trabajo Social ha creado más bien un mero relato de "acontecimientos", haciendo lo que la Escuela de Los Anales llamaba histoire événementielle (Burke, 1996).

Sin embargo, nosotros nos alejamos también de la postura que tiene Illanes sobre la historia del Trabajo Social en Chile. Sin siquiera pronunciarnos sobre la postura conceptual o ideológica de la autora, creemos que su perspectiva de análisis no permite una interpretación compleja de los procesos profesionales y, en sentido más amplio, de la historia social chilena. Por ser deudora de una crítica tan frontal a la modernidad y por sostener una visión del poder que se compromete tanto con el primer Foucault, Illanes solo puede entender a las primeras visitadoras como instrumentos de aplicación de las políticas sociales del Estado -como un Estado ampliado, en ese sentido-, y concluir que dichas visitadoras no fueron más que una segunda fase en el proceso de cooptación del pueblo, es decir, herederas directas de las señoras aristócratas o burguesas de las primeras décadas del siglo XX. En definitiva, las visitadoras fueron un instrumento de mediación no conflictiva que apaciguaba el conflicto de clase y fortalecía el pacto social capitalista. Señala: "dado el profundo distanciamiento y conflicto entre ricos y pobres y entre las clases sociales, producido en el curso de la consolidación capitalista, el deseo de una 'voluntad de aproximación' -tal como lo planteó la iglesia hacia fines del siglo XIX, por ejemplo- era un idealismo o una abstracción que no tenía eficacia real. El concepto político de aproximación entre las clases, en tanto buscaba ser oponente al concepto de lucha de clases, era sin duda un concepto 'no-revolucionario' y, para serlo, necesitaba de una ideología sustentada en un cuerpo de verdades científicamente formuladas, de una utopía convincente, de un cuerpo de militantes activos y de una estrategia $o$ vía que permitiese llevarla a la práctica; este último elemento era indispensable, sin el cual todos los otros factores caían al vacío" (Illanes, 2007, p. 446). Ese "elemento", dice Illanes, fueron las visitadoras sociales.

1 La traducción es mía.

2 Dentro de estos textos podemos citar: Ayalón, N. (1984); Quiroz, M. (2000); Quiroz, M. (1998); Alvariño, P. (1984); Jiménez, M. (1979); Jiménez, M, (1982). 
El periodo que abordamos ha sido calificado por la literatura existente como de "profesionalización", aun cuando esta denominación ha sido trabajada muy débilmente. En específico, se ha entendido que para el caso del Trabajo/Servicio Social, "profesionalizarse" ha significado el paso desde la "caridad" a la "asistencia" y no necesariamente, como en otras disciplinas, el logro de un aparataje conceptual propio, la adquisición de determinados métodos de actuación o habilidades especializadas, prestigio social elevado en comparación con el trabajo manual (Broman, 1995, p. 835) ${ }^{3}$, estándares éticos de nivel avanzado (Kunzel, 1988, p. 22 y sgtes.), o, por último, un cierto proceso de institucionalización de las prácticas (González Leandri, 1999, p. 15 y sgtes.). En ese sentido, hablar de que el Trabajo Social se profesionalizó en Chile desde los años '20 del siglo $\mathrm{XX}$ solo ha venido a ser parte del discurso estatuido por la historia y se ha reducido en su análisis al proceso de formación ceñido a una estructura formal de aprendizaje.

Valiéndonos de esta apreciación, podemos sostener que este proceso de profesionalización se inició en Chile el año 1925 con la fundación de la primera Escuela de Servicio Social -primera también en Latinoamérica y en habla hispana-, al alero de la Junta de Beneficencia y continuó con la creación de la Escuela Elvira Matte de Cruchaga, de inspiración católica, el año 1929. En Europa y EEUU el Servicio Social "científico" no era mucho más antiguo. En 1919 se había creado la Escuela de Servicio Social de Nueva York (como continuación de la Escuela de Filantropía, fundada en 1898) y en Europa se había abierto la primera escuela en Amsterdam, en 1899.

La Escuela de la Beneficencia formó a las primeras visitadoras sociales chilenas y contempló un plan curricular que duraba dos años y en el que se enseñaban materias como Instrucción Cívica, Psicología, Higiene y Deontología, Atención de Enfermos, Estadística y Técnicas de Oficina, Legislación, Beneficencia, Puericultura, Contabilidad, entre otros ${ }^{4}$. Al final de cada año lectivo las alumnas desarrollaban los "semestres de verano", en los cuales se realizaban prácticas de servicio social en instituciones de beneficencia pública y privada; al final de la carrera se entregaba una memoria y se rendía un examen de título.

La Escuela Elvira Matte de Cruchaga no fue demasiado distinta, a pesar de que pretendió constituirse en una alternativa a la "neutralidad laica" de la Escuela de la Beneficencia y que "tendría por fin preparar y titular Visitadoras Sociales, que podrían servir en las instituciones públicas y privadas. Su formación sería sobre la base de la Doctrina Católica y de las ciencias necesarias para la formación técnica" (Izquierdo, 1932).

En síntesis, se trataba de dos escuelas que compartían el espíritu modernizador del Estado asistencial, que se empeñaban por procurar una intervención científica de la miseria, pero que se diferenciaban también en algunos aspectos: la Escuela de la Junta de Beneficencia aspiraba a un tratamiento neutro de los problemas sociales y se encontraba mayormente impregnada del énfasis higienista de las políticas sociales y del modelo biomédico de tratamiento; la Escuela Elvira Matte, por su parte, rechazaba la neutralidad y buscaba la formación de profesionales explícitamente inspirados por valores cristianos, con un énfasis mayor en los "problemas morales" que en los higiénicos.

A las anteriores se agregó, el año 1940, la Escuela Lucio Córdova, la primera de carácter público y dependiente del Ministerio de Educación. Tuvo sedes en Santiago, Concepción y Temuco y desde 1948 fueron anexadas a la Universidad de Chile con dependencia de la Facultad de Ciencias Jurídicas y Sociales. Como se ha señalado: "La carrera de asistente social se inició en estas Escuelas de Servicio Social con un régimen de tres años de estudio académico, cuyo plan de estudios buscó armonizar los conocimientos específicos de la metodología del Servicio Social Profesional y de otros ramos profesionales médicos, de derecho y de algunas ciencias sociales, con los conocimientos complementarios sobre educación familiar, bibliotecomanía, orientación de lecturas, etc." (Revista de la Escuela de Servicio Social "Doctor Lucio Córdova", 1966, p. 8). En el tercer año se realizaba un trabajo práctico y este daba paso a una memoria de prueba para obtener el título de Asistente Social.

\section{La formación de las primeras escuelas bajo el influjo europeo}

La formación y estructuración de las primeras escuelas de Trabajo Social en Chile estuvo marcada por haber sido copias de los modelos que ofrecían las escuelas homólogas en Bélgica y trajeron directoras europeas para que encabezaran la formación de las

\footnotetext{
3 Las características señaladas las toma Broman de Charles McClelland, en su texto The German Experience of Proffesionalization (Camdridge, 1991).

4 En la Escuela Elvira Matte se agregaban los ramos de Ética y Religión.
} 
nuevas visitadoras sociales durante los años 20 .

El compromiso sostenido con la resolución de los problemas sociales de parte de los sectores profesionales que aspiraban a dirigir el país -principalmente médicos-, los llevó a buscar en otros países algunas alternativas y ejemplos a seguir; allí se encontraron con que en Europa el espacio de la filantropía y la caridad se hallaba ya profesionalizado y que eso brindaba a las políticas sociales una "aplicación" más efectiva y moderna. En pocas palabras, el ejemplo europeo demostraba que la "profilaxis social" permitía un enfrentamiento integral de los problemas y que las temáticas sociales, médicas y jurídicas pasaban a ser "resueltas" por una sola mirada profesional. A la muerte de Alejandro del Río, médico fundador de la primera escuela de Servicio Social en Chile, Gabriel Amunátegui comentaba lo siguiente:

"A fines de 1924 recibimos una citación para asistir a una reunión en casa de don Ismael Valdés Valdés, Presidente en esa época de la Junta de Beneficencia. Ahí nos encontramos, entre otros, con los doctores Gregorio Amunátegui, Alejandro del Río, Eugenio Cienfuegos, Eugenio Díaz Lira, con los profesores universitarios Raimundo del Río y Moisés Poblete Troncoso. Don Ismael, con su característica modestia, nos dijo que el Doctor del Río le había conversado, reiteradamente, acerca de la creación en Chile de un organismo nuevo, desconocido en América, de una escuela de Servicio Social y que le había indicado, asimismo, los nombres de algunas de las personas que podían ayudarle en esa obra. Los concurrentes, en su mayoría, recibieron la noticia con extrañeza, con interesada curiosidad. (Después, recordando ese primer gesto -origen de una Escuela que es modelo en su género-, nos confesamos varios nuestro desconcierto ante la petición de cooperación que recibimos).

El Dr. Del Río, recorriendo pausadamente el escritorio donde nos encontrábamos, nos dio una lección de "Servicio Social" [...] "Recuerdo fielmente que ante una interrupción aclarativa, nos dijo: 'El problema social es doble: de una parte, el aspecto médico e higiénico, y de la otra, la cuestión legal. Imagínense ustedes el 'caso' -y vaya que nuestra Escuela, en sus 15 años de ininterrumpida tarea, ha acudido a centenares y centenares de 'casos sociales', después que el Dr. Del Río nos exhibiera, en esos lejanos días del año 1924 el hipotético caso, subrayado mil veces por la realidad)-, de un enfermo tuberculoso que llega al Hospital. Una cosa es la atención de ese enfermo. Mas, ese hombre ha dejado un hogar, que es menester preservar. Hay que llegar hasta él y acudirlo. Prevenir el posible contagio. Y, además, -en esos días empezaba la vigencia de la legislación social-, seguramente se trata de uniones ilegítimas, que es menester regularizar. Reconocer hijos, legalizar uniones'. Y, de ese modo simple, el profesor del Río esbozaba la finalidad de la escuela proyectada. Entusiasmado con ella, contagiados con su fervor, convencidos de la función social que estaba llamada a desempeñar, ofrecimos gustosos todos los allí reunidos nuestra modesta colaboración" (Amunátegui, 1939, p. 6-7).

Alejandro del Río se había inspirado en las ideas que René Sand, un higienista francés, había transmitido en el Cuarto Congreso Panamericano del Niño, que se había realizado en Santiago en septiembre de 1924. Alejandro del Río supo ver qué tipo de organización y orientación debía tener la nueva Escuela. Primero eligió el terreno donde esta debía funcionar, dibujó los planos, trazó las líneas generales del plan de estudios y de los programas, e hizo contratar como directora a Mme. Bernier, una profesora belga que se había especializado en problemas sociales.

El primer curso, dictado el año 1925, tuvo 42 alumnas que se sometieron a un proceso de selección que implicó una evaluación de sus antecedentes familiares y condiciones personales y en el cual se les pedía a las postulantes haber rendido el tercer año de humanidades, pagar la fianza estipulada y demostrar una "vida y moral" acorde con los valores profesionales.

Algo parecido aconteció en la Escuela Elvira Matte de Cruchaga. Las hermanas Izquierdo Phillips fueron comisionadas el año 1927 para que estudiaran en Bélgica la existencia y peculiaridad de las escuelas católicas y tomaron contacto con la alemana Luise Jörinssen, que viajó a Chile a desempeñarse como primera directora.

El primer año se aceptaron 30 postulantes, pero se seleccionaron solo 20 luego de un trimestre de prueba. El ingreso implicaba el pago de la fianza, tener entre 20 y 35 años, haber cursado los seis años de humanidades con buen rendimiento, demostrar conocimientos de manejo del hogar y de economía doméstica y presentar la recomendación de un cura.

En estos primeros años, ambas escuelas promovieron una formación orientada por los principios higienistas de la biopolítica; estos entendían que la política social debía dirigirse primordialmente al ataque de problemas sanitarios (tuberculosis, enfermedades venéreas, alcoholismo, entre otros) con la perspectiva de "prevenir" más que "curar":

"El esfuerzo actual de los filántropos y de todos los organismos de asistencia tiende, sobre todo, de organizar en este dominio, a la asistencia preventiva, a fin de reducir cada vez más la par- 
te que toca a la asistencia curativa y de suprimir las medidas paliativas que fueron, durante largo tiempo, los únicos remedios empleados para curar todos los infortunios, todas las miserias" (La Escuela de Servicio Social de Santiago de Chile, 1927, p. 8).

Otra influencia clara recibida en estos primeros años de formación estuvo dada por la idea de que la creación de escuelas garantizaba el paso de la "caridad a la asistencia" y esto se inscribía en la tendencia positivista y funcionalista de las profesiones, de acuerdo a la cual estas eran portadoras de una verdad "objetiva", que se manifestaba técnicamente a través de un saber profesional neutro y científicamente fundado, garante de una solución "moderna" a los problemas sociales. Como señalaba Leo Cordemans, segunda directora de la Escuela de la Beneficencia, el paso de la caridad a la asistencia, a través de la filantropía, era el tránsito desde la acción basada en la buena voluntad hasta otra de carácter científico que "[...] encierra las reglas del diagnóstico social, las del tratamiento basada sobre las medidas preventivas o curativas, con exclusión de los procedimientos simplemente paliativos" (Cordemans, 1927, p. 7).

Cordemans estaba convencida de que la visitadora social estaba llamada a cumplir esa tarea "científica", pues "...su ayuda no se limita, como otras veces, a dádivas que sostienen a menudo la causa del mal, sino que envuelve el análisis de la situación material, profesional, moral de una familia, y el llamado a las influencias, obras, poderes, que pueden concurrir al mejoramiento" (Cordemans, 1927, p. 7).

\section{La transición hacia la influencia norteamericana}

A pesar de que ya el año 1924 se reconocía a las escuelas norteamericanas como experiencias loables y dignas de imitar y se las avizoraba como referente (Sand, 1924), hemos visto que en esos primeros años de profesionalización fue mayor la preponderancia de Europa.

La influencia norteamericana en el Trabajo Social chileno arrancó con fuerza recién el año 1941, con la participación de una delegación chilena en la Conferencia Anual de Trabajo Social que se desarrollaba en la ciudad de Atlanta.

La Asociación de Escuelas de Servicio Social de Estados Unidos se decidía, por primera vez el año 1941, a invitar a un encuentro latinoamericano. Asistieron quince escuelas, incluyendo la chilena, a una reunión de más de un mes, que implicaba un Congreso, visitas a ocho ciudades en Estados Unidos y la observación guiada de distintas escuelas y obras sociales del país.
"En el programa, que abarcó todo el mes de Junio, estaban comprendidos la asistencia al Congreso, una gira de estudios y una discusión final, con las organizaciones centrales de Washington, de puntos de vista y de resoluciones" (Tocornal, 1941, p. 162).

A pesar de que en el relato no se declaran las fuentes de financiamiento, se deduce de los documentos que el gobierno del norte invitaba a los países latinoamericanos a participar del evento pagando gran parte o la totalidad de los gastos. El encuentro implicaba numerosas actividades de recepción y camaradería, reuniones con autoridades locales y de los países visitantes (embajadores, entre otros), alojamiento de las delegaciones en hoteles de adecuado estándar, viajes entre ocho ciudades, comidas, viáticos y todos los gastos derivados del Congreso propiamente tal.

La cuestión se transformó, a todas luces, en un acontecimiento de carácter nacional para el gobierno norteamericano. Las directoras de las escuelas de Latinoamérica fueron convocadas por la confluencia de organismos del ámbito del Trabajo Social y otros del Ejecutivo:

\begin{abstract}
"Su visita fue arreglada por el Consejo de Defensa Nacional a través de su Oficina de Coordinación para las relaciones culturales y comerciales entre las Repúblicas de la América; con la cooperación del Departamento de Estado, incluyendo nuestras misiones diplomáticas en las otras Repúblicas Americanas, y la Oficina del Niño" (La Conferencia de Servicio Social de Atlantic, 1941, p. 177).
\end{abstract}

Los discursos nos hacen pensar que para el gobierno norteamericano la reunión significaba tener presentes a los países latinoamericanos en torno a un tema que se ubicaba a medio camino entre los intereses políticos y los sociales. Las escuelas de Servicio Social representaban, como lo han sostenido algunos autores, la forma en que el Estado llegaba a los pobres y la manera en que resolvía también la "cuestión social" que años antes había desestabilizado a la mayor parte de las sociedades occidentales. La política social era, de este modo, una expresión del nuevo pacto social fordista, sustentado en un acuerdo con la democracia y el capitalismo. En razón de lo anterior, los discursos convencían a los asistentes de la importancia de consolidar los valores de convivencia en orden, alertaban sobre los peligros de la guerra y generaban una especial solidaridad entre el "norte" y el "sur":

\footnotetext{
"Deseamos que todos vuestros días en nuestro país sean felices y completos en realización de los fines de nuestro viaje. Ojalá que en este mes dedicado a una labor común, nosotros del
} 
Norte y vosotros del Sur, hayamos trabajado tan unidos que nuestra labor sea una fuente de fortaleza para nuestros espíritus, impregnados de los sentimientos y principios de justicia, de caridad y de amistad. Ojalá que en esta manera se forme una verdadera defensa social contra el peligro terrible que hoy ensombrece el mundo entero, una defensa de hogares, de familia, de niños, tan fuerte como el espíritu de América. Este espíritu y la fe en el destino de nuestra civilización libre, únicamente asegurarán a los niños del Nuevo Mundo un futuro digno de las aspiraciones del pasado heroico, un pasado que ha puesto en nuestras manos y nuestros corazones la libertad y la seguridad de nuestras patrias del Norte y del Sur"5.

Los aspectos señalados hasta el momento no serían tan significativos si no fuesen por las consecuencias que ellos tuvieron en los años posteriores para el Trabajo Social chileno. En lo inmediato, el viaje hizo concluir a Luz Tocornal, Directora de la Escuela de Servicio Social de la Junta de Beneficencia, que el Servicio Social de Estados Unidos se había convertido, en los últimos diez años, en el más importante a nivel mundial y que "sus publicaciones, que son las que han llegado con mayor regularidad, constituyen nuestra mayor fuente de inspiración" (Tocornal, 1941, p. 158).

Señalaba, más delante, que "evidentemente" el Servicio Social estadounidense se situaba en un nivel de desarrollo superior y que este se había alcanzado superando los problemas que la profesión tenía en Chile por aquellos años. Cuatro elementos destacaba Tocornal: la especificidad de la función de la visitadora social, la comprensión de parte de médicos y enfermeras, la organización armónica de los servicios y la preparación especializada (Tocornal, 1941, p. 160). Se explayaba del siguiente modo:

\footnotetext{
"No pretendo analizar los factores que dan superioridad sobre el nuestro, al Servicio Social de los Estados Unidos y en los que se cuentan, de seguro, mejores condiciones económicas, culturales y de otra especie. Señalaré, sin embargo, algunos: 1) Mejor definición de las funciones, a consecuencia de lo cual, no se le pueden confiar a las Visitadoras misiones para las que no está destinada, o especialmente calificada, y ella, a su vez, tiene concepto más claro del papel que le corresponde dentro de la Institución donde trabaja; 2) Relaciones profesionales armónicas, que permiten darse la mano de un establecimiento a otro, aunar los esfuerzos, adaptarse a las peculiaridades de una jefe o una colega y ver en ésta
}

o aquélla a la profesional, prescindiendo, si es necesario, de la persona; 3) Mayor afán de progreso, que se traduce en lectura más asidua, en frecuentes congresos y reuniones, en cursos de perfeccionamiento, en literatura en cierto modo pródiga y en variadas investigaciones.

Si se atiende a que nuestra actitud es, a mi entender, más fervorosa y a que aquellas imperfecciones no son fatales, sino por el contrario, muy susceptibles de corregir, la lección recibida ha de tenerse por estimuladora. Resulta alentador, además, comprobar que nosotros vamos siguiendo el mismo camino y que afrontamos escollos y desilusiones que no son peores de los que ellos debieron esperar" (Tocornal, 1941, p. 167).

De esta manera, y como ha puntualizado Stefan Rinke (2004), Estados Unidos se presentaba a ojos de las visitantes latinoamericanas como una especie de viaje al futuro: la propia realidad aparecía como un "pasado" que había que superar y avanzar en la dirección fijada por el punto de comparación foráneo.

El encuentro de Atlantic City generó otra consecuencia específica, que fue un acuerdo para ofrecer becas y perfeccionamiento a visitadoras sociales de Latinoamérica. Al año siguiente, ya se encontraban dos chilenas estudiando en Estados Unidos.

Laura Vergara Santa Cruz, becada en la Escuela de Servicio Social de Nueva York, escribía, en 1942, un artículo muy significativo titulado "La política del buen vecino en acción", con motivo de la invitación que habían recibido ella y una delegación de varios países latinoamericanos de parte de la Children's Bureau y la Oficina del Coordinador de Asuntos Interamericanos, para participar en el Congreso Panamericano del Niño en Washington. En la misma tónica que el encuentro de Escuelas del año anterior, la invitación contemplaba la asistencia al Congreso, la visita a obras y programas sociales diversos y el traslado hacia Nueva Orleans, donde se realizaba el Congreso Nacional de Servicio Social. También en este caso, las actividades propiamente académicas y vinculadas al tema del Congreso fueron complementadas con otras de carácter oficial, que contemplan una visita hasta la Casa Blanca, donde fueron recibidas por la Primera Dama, Eleanor Roosevelt. Hubo diversas reuniones con delegaciones extranjeras, diplomáticos y hasta con el Presidente de la República de Perú, de visita por aquellos días en Estados Unidos.

5 Palabras pronunciadas por Katherine Lenroot, Directora de la Oficina del Niño del Departamento del Trabajo en Washington. Citadas en: La Conferencia de Servicio Social de Atlantic City, 1941, p. 178. 
En todas las reuniones en Nueva York y las que con posterioridad se realizaron en Nueva Orleans, el tema siempre fue el rol del Servicio Social en la Post Primera Guerra Mundial y en la consolidación de la democracia. En el Congreso Nacional de Servicio Social expuso la Directora del Departamento de Investigación de la Foering Policy Association, con el tema "Después de la Victoria... ¿qué?", aludiendo a las consecuencias contemporáneas de la I Guerra. Y, como señala Vergara:

\begin{abstract}
"Las sesiones siguientes abordaron los problemas del Sur de los EEUU, en su aspecto social y económico, el standard de vida americano en tiempo de guerra y en la sesión de clausura, Miss Gertrude Springer, editora del Survey, delineó a grandes rasgos "La responsabilidad del Trabajador Social en una democracia" (Vergara Santa Cruz, 1942, p. 86).
\end{abstract}

La influencia norteamericana se notó también en esos años cuando se fundó en 1942, la Escuela Lucio Córdova, primera escuela pública de formación de asistentes sociales. Á diferencia de las anteriores, que habían imitado el ejemplo belga, esta derechamente se inspiraba en la formación norteamericana:

"Para formalizar en el momento oportuno esta nueva modalidad de enseñanza en Chile, su Excelencia y el Ministro de Educación Pública, Dn. Rudecindo Ortega, enviaron en comisión de estudios a Estados Unidos de América cuatro visitadoras sociales tituladas, para perfeccionar sus conocimientos sobre servicio social, quedando comprometidas a enseñar los principios fundamentales de esta ciencia social en las escuelas especiales que se fundarán al regreso de ellas. Me cupo el honor de formar parte de ese grupo, y de quedar designada para enseñar en la Escuela de Santiago. Hice el curso de perfeccionamiento en The New York School of Social Work, la Escuela de Servicio Social de mayor renombre en el mundo entero..." (Olmos Hansen, 1943, p. 249)

En definitiva, ya para inicios de la década de los '40 se había entrado en una corriente de influjos que no se detendría en años posteriores y que no involucraba solo el caso del Servicio Social. Los médicos emprendían por aquellos años verdaderas peregrinaciones a las universidades norteamericanas ${ }^{6}$ y se declaraba que la política social no podía ser ya un patrimonio de cada nación por separado, sino producto del flujo constante de intercambios mutuos:
"Para conquistas generalizadas que se reflejen en paz durable, la política social excede el dominio privativo de cada país y desborda el radio internacional. En sus tareas básicas, para abandonar la zona de las aspiraciones y convertirse en hecho perdurable, no le basta un programa interno. Como alguien ha apuntado, debe renunciar a la antigua creencia de que para dificultades propias bastan remedios nacionales, y concebir y practicar una colaboración internacional que permita la elevación paralela del nivel de vida de grupos similares de naciones distintas" (Ivovich, 1942, p. 140-141).

Para el caso del Trabajo Social, estas visitas, la participación en Congresos y las becas de formación tuvieron consecuencias académicas y prácticas para el Trabajo Social chileno. Y aunque no es objetivo de este artículo mostrar lo que ocurriría en años posteriores, sí podemos señalar que se imitaron los métodos profesionales de intervención: al tradicional método de Casos (que también se había desarrollado en Estados Unidos, a partir de Mary Richmond), las visitantes manifestaron su admiración por el trabajo con Grupos y con Comunidades y estos se convirtieron en las formas prototípicas de intervención desde el Servicio Social. En los años 60 se adhirió al modelo tecnológico que el norteamericano Greenwood expuso y enseñó en la Escuela de la Universidad de Chile primero y que luego se extendió a las otras Escuelas ${ }^{7}$. Y, para mayor redundancia, la carrera misma pasó a denominarse "Trabajo Social", en franca imitación de las social workers estadounidenses.

\section{Reflexiones finales}

Como hemos intentado mostrar en el presente artículo, los primeros años de profesionalización del Trabajo Social chileno no pueden entenderse si no es en referencia a las influencias internacionales. Las dos primeras escuelas fueron fundadas por inspiración de sendas visitas a Europa y sus directoras fueron trabajadoras sociales de origen extranjero. Los emplazamientos, el curriculum de formación y el sistema de prácticas, entre otros, se hizo siguiendo el ejemplo que proporcionaban los países europeos y los modelos de enseñanza se inspiraron en esos otros esquemas que pretendían pasar desde la "caridad" a la "asistencia". Destaca en esos primeros años la presencia de Luz Tocornal y Moisés

6 Reflejo de esto son las publicaciones consignadas en la Revista de Asistencia Social. Entre ellas podemos destacar: Acuña Zamora, M. (1942); Araneda, G. (1943); Bravo, A. (1943); Santa María, J. (1943).

7 Véase con más detalle en: Greenwood, E. (1967/1968); Aylwin, N. (1976). 
Poblete en la Primera Conferencia Internacional de Servicio Social de 1928, en el marco de la Quincena Social de París. Tocornal afirmaba:

\begin{abstract}
"Intimidada me sentí al llegar, única de mi país y viniendo de tan lejos, me miraban con asombro, como algo exótico, pero al conversar, luego comprendimos lo cerca que estábamos espiritualmente, ya que a todas nos guiaba el mismo y grande ideal" (Tocornal, 1928, p. 271).
\end{abstract}

Si en esos primeros años se evidencia un influjo de Europa y especialmente de Alemania, Austria, Dinamarca y, sobre todo, de Bélgica, hacia los años '40 se produce una revitalización de los contactos internacionales. Por esos años notamos las primeras referencias a otros países latinoamericanos y crece en importancia, tal como lo hemos reseñado, el influjo del Servicio Social norteamericano.

El paso desde una a otra puede explicarse a partir de la "decadencia europea" luego de la Primera Guerra Mundial y la subida correlativa que empezó a experimentar Estados Unidos. La devastación del continente europeo, el comienzo de los regímenes totalitarios y la nueva guerra mundial hacían que ya para los años 40 la representación del progreso y el desarrollo se hubiera desplazado hacia el norte de América.

Por otro lado, nos situamos históricamente en la época de auge del panamericanismo y de la política del "buen vecino" de Roosevelt, con su acento en una interpretación de la doctrina Monroe desde la lógica del respeto mutuo para la consolidación de la democracia. En el concierto de estas ideas, las delegaciones latinoamericanas fueron invitadas a compartir el esplendor norteamericano y muchas de ellas se sintieron parte de un pasado que, de proyectarse linealmente, le auguraba al Servicio Social de los países latinoamericanos un próspero porvenir. Los hechos que hemos analizado se sitúan dentro de los que se ha denominado "imperialismo como proyecto cultural" y se basan en el supuesto de que el campo de intervención de Estados Unidos al sur de Panamá se efectuó con reglas diferentes a las de la invasión militar y la anexión territorial que caracterizó a la política norteamericana con América Central y el Caribe. En América del Sur debían primar los argumentos del conocimiento, la persuasión y los mercados (Salvatore, 2006), pues Estados Unidos se representaba a la región como terreno de inversiones potenciales, como mercado de sus bienes y productos y como "receptáculo para el excedente moral de sus reformadores" (Salvatore, 2006, p. 26).

En años posteriores no hicieron sino reforzarse estos vínculos y se solidificó una relación estrecha con el Servicio Social norteamericano. Las Escuelas chilenas adoptaron los métodos de intervención del país del norte y se mantuvieron aquí con fuerza las "metodologías" de caso, grupo y comunidad que caracterizaron al servicio social en EE.UU. La misma denominación de "Servicio Social" se trocó años más tarde por la de "Trabajo Social", siguiendo el ejemplo del Social Work estadounidense.

En este trabajo no hemos querido ser exhaustivos respecto de todas las dimensiones que tuvo la relación entre Servicio Social estadounidense y chileno, sino solo mostrar cómo se inició y con qué representaciones sociales se manejó. Como ha señalado Ricardo Salvatore, cuando nos alejamos de los modelos dependentistas e imperialistas tradicionales, podemos conocer lo que él denomina el "Imperio Informal Norteamericano", es decir, la "maquinaria que diseminaba variados argumentos y razones de dominio, contaba con numeroso mediadores o agentes y necesitaba de diversos tipos de representaciones, por momentos contradictorias" (Salvatore, 2006, p. 19). Hemos visto así que las visitadoras sociales fueron parte de esa corriente de agentes que, incluyendo a médicos, abogados y enfermeras, viajaron a Estados Unidos, se admiraron de su desarrollo, desearon seguir su senda y, al mismo tiempo, actuaron creyendo que "se hace indispensable que miremos para aprender, sin olvidar de que posteriormente actuaremos entre nosotros con nuestras propias idiosincrasias y limitaciones de medios humanos y materiales" (Santa María, 1943, p. 384).

\section{Fuentes y bibliografía \\ Fuentes}

ACUÑA ZAMORA, M. (1942). Oportunidades para los médicos internistas en Estados Unidos. Revista de Asistencia Social, XI, 3.

ALVARIÑO, P. (1974). El proyecto como modelo de acción social. Revista de Trabajo Social, Pontificia Universidad Católica de Chile, 11.

ALVARIÑO, P. (1984). Diez años después de la reconceptualización profesional. Revista de Trabajo Social, Pontificia Universidad Católica de Chile, 42.

AMUNÁTEGUI, G. (1939). El doctor Alejandro del Río y los orígenes de la Escuela de Servicio Social". Servicio Social, XIII, 1.

ARANEDA, G. (1943). Los centros de salud en Estados Unidos de Norteamérica. Revista de Asistencia Social, XII, 1.

AYALÓN, N. (1984). Del asistencialismo a la post-reconceptualización: las corrientes del Trabajo Social. Revista de Trabajo Social, Pontificia Universidad Católica de Chile, 42. 
AYLWIN, N.; POBlete, M.; SOlAR, M. O. (1970). Orientaciones para la acción del trabajo social. Revista de Trabajo Social, Pontificia Universidad Católica de Chile, 1.

AYLWIN, N.; RODRÍGUEZ, V. (1971). Qué es el trabajo social en la actual perspectiva histórica chilena. Revista de Trabajo Social, Pontificia Universidad Católica de Chile, 2.

AYLWIN, N. (1976). Evolución histórica del Trabajo Social. Revista de Trabajo Social, Pontificia Universidad Católica de Chile, 18.

BRAVO, A. (1943). Organización gremial de la lucha contra la tuberculosis en Estados Unidos. Revista de Asistencia Social, XII, 2-3.

CORDEMANS, L. (1927). De la caridad al Servicio Social. Servicio Social, I, 1-2.

EDITORIAL "Servicio Social busca respuestas" (1970). Revista de Trabajo Social, Pontificia Universidad Católica de Chile, 1.

GREENWOOD, E. (1967/1968). Ciencia Social y Servicio Social. Una segunda mirada. Revista de la Escuela de Servicio Social de Santiago, Universidad de Chile, 5-6.

HISTORIA DE LA ESCUELA DE SERVICIO SOCIAL 'Dr. Lucio Córdova' de la Universidad de Chile Santiago (1966). Revista de la Escuela de Servicio Social de Santiago, Universidad de Chile, 4.

IVOVICH, E. (1942). La nueva política de seguridad social. Revista de Asistencia Social, XI, 3.

IZQUIERDO, R. (1932). Fundación y desarrollo de la Escuela de Servicio Social 'Elvira Matte de Cruchaga'. Memoria para optar al título de Visitadora Social de la Escuela Elvira Matte de Cruchaga. Santiago.

JIMÉNEZ, M. (1979). Bodas de oro de la Escuela de Trabajo Social de la Universidad Católica de Chile. Revista de Trabajo Social, Pontificia Universidad Católica de Chile, 29.

JIMÉNEZ, M. (1982). Nueve años de historia de la Escuela de Trabajo Social: 1973- 1982. Revista de Trabajo Social, Pontificia Universidad Católica de Chile, 38.

LA CONFERENCIA DE SERVICIO SOCIAL DE ATLANTIC CITY (1941). Servicio Social, XV, 4.

LA ESCUELA DE SERVICIO SOCIAL DE SANTIAGO DE CHILE (1927). Servicio Social, I, 1-2.

OLMOS HANSEN, E. (1943). Las Escuelas de Servicio Social del Ministerio de Educación. Revista de Asistencia Social, XII, 2 y 3.

QUIROZ, M. (1998). Antología del Trabajo Social chileno. Universidad de Concepción, Facultad de Ciencias Sociales, Departamento de Servicio Social. Proyecto de Docencia 97-158. Quiroz, M. (2000). Apuntes para la historia del Trabajo Social en Chile. Boletín Electrónico Surá. Recuperado el 13 de abril de 2008 del sitio http:// www.ts.ucr.ac.cr/suradoc.htm
SAND, R. (1924). El Servicio Social. Revista de Beneficencia Pública, VIII, 2.

SANTA MARÍA, J. (1943). Observaciones sobre los servicios dietéticos en hospitales norteamericanos. Revista de Asistencia Social, XII, 4.

TOCORNAL, L. (1928). Impresiones del Congreso Internacional de Servicio Social. Servicio Social, II, 4.

TOCORNAL, L. (1941). Informa sobre Comisión de Estudios a Estados Unidos. Servicio Social, XV, 3.

VERGARA SANTA CRUZ, L. (1942). La política del buen vecino en acción. Servicio Social, XVI, 1-2.

\section{Referencias bibliográficas}

BROMAN, T. (1995). Rethinking Professionalization: Theory, Practice, and Professional Ideology in Eighteenth-Century German Medicine. The Journal of Modern History, 67.

BURKE, P. (Ed.) (1996). Formas de hacer historia. Madrid: Alianza Universidad.

CONRAD, S.; ECKERT, A. (2007). Historia Global, Globalización, Múltiples Modernismo: Notas sobre la historiografía del mundo moderno. En: Conrad, S.; Eckert, A.; Freitag, U. Globalgeschichte. Theorien, Ansätze, Themen. Frankfurt A. M.

GONZÁLEZ LEANDRI, R. (1999). Las profesiones. Entre la vocación y el interés corporativo. Madrid: Editorial Catriel.

ILLANES, M. A. (2007). Cuerpo y sangre de la política. La construcción histórica de las visitadoras sociales en Chile, 1887- 1940. Santiago: Lom Ediciones.

JOSEPH, G. (2005). Encuentros cercanos. Hacia una nueva historia cultural de las relaciones entre Estados Unidos y América Latina. En: Salvatore, R. (Comp.), Culturas Imperiales. Experiencia y representación en América, Asia y Africa. Rosario: Beatriz Viterbo editora.

JOSEPH, G. (2006). Close Encounters. Toward a New Cultural History of U.S.- Latin American Relations. En Joseph, G. (Ed.), Close Encounters of empire. Writing the cultural history of U.S.- Latin American Relations. Durham.

KUNZEL, R. (1988). The Professionalization of Benevolence: Evangelicals and Social Workers in the Florence Crettenton Homes, 1915 to 1945. Journal of Social History, 22, 1 .

RINKE, S. (2004). Reconstrucción de la norteamericanización. Traducción no publicada del libro Rinke, S., Encuentros con el Yanki: Norteamericanización y cambio sociocultural en Chile, 1898- 1990. Köln: Böhlau.

SALVATORE, R. (2006). Imágenes de un imperio. Estados Unidos y las formas de representación de América Latina. Buenos Aires: Editorial Sudamericana. 